\title{
A follow-up study to a randomised control trial to investigate the perceived impact of mindfulness on academic performance in university students
}

\author{
Short title: Students' perceptions of the influence of mindfulness on \\ academic performance:
}

\section{Accepted by Journal of Counselling and Psychotherapy Research}

\begin{abstract}
Sebastian J.M. Bóo1 ${ }^{1}$, Jasmine Childs-Fegredo ${ }^{2}$, Steven Cooney ${ }^{3}$, Bella Datta ${ }^{4}$, Géraldine Dufour ${ }^{5}$, Peter B. Jones ${ }^{6}$, Julieta Galante ${ }^{7}$

${ }^{1}$ Student Wellbeing Service, Teaching \& Learning Centre and Department of Behavioural \& Psychological Sciences, London School of Economics and Political Science, U.K. ORCID 0000-0002-8579-203x

2 Research Associate, Institute of Public Health Primary Care, Department of Psychiatry, University of Cambridge, U.K. ORCID 0000-0002-8579-203x
\end{abstract}

${ }^{3}$ Steven Cooney, MSc in organisational psychological student, Birkbeck College, University of London, U.K. ORCID 0000-0002-0011-5348

${ }^{4}$ Psychological Wellbeing Practitioner, Hertfordshire Partnership University NHS Foundation Trust, U.K.

${ }^{5}$ Head of Counselling, University Counselling Service, University of Cambridge, U.K.

${ }^{6}$ Professor of Psychiatry, and Director, NIHR CLAHRC East of England, Department of Psychiatry, University of Cambridge, U.K. ORCID 0000-0002-0387-880X ${ }^{7}$ Research Fellow Department of Psychiatry, University of Cambridge, U.K. ORCID 0000-0002-4108-5341

${ }^{*}$ Correspondence should be addressed to Sebastian J. M. Bóo. Student Wellbeing Service, London School of Economics and Political Science, Houghton Street, London WC2 2AE, United Kingdom (s.boo@Ise.ac.uk)
Abstract:
1 Objectives
Mindfulness research in education has focussed on its potential to support student well-being. There is a paucity of research on the interaction between mindfulness and academic performance. This qualitative study builds on results of the largest randomised control trial of mindfulness in education to date which suggested mindfulness can have mixed effects on academic performance. A more in-depth understanding of the relationship between mindfulness and academic performance is therefore needed to ascertain if, how and for which students, mindfulness facilitates academic performance. The objective of the study was to capture students' perceptions of the impact of mindfulness on their academic performance. 


\section{Methods}

Thematic analysis was applied to data obtained by six in-depth interviews from three higher and three lower performing undergraduate participants in the mindfulness intervention arm of the Mindful Student Study randomised control trial.

\section{Results}

Three themes emerged, whereby five students described mindfulness having a positive impact on their academic performance. One student felt mindfulness had an initial negative impact on academic performance. All students felt mindfulness enhanced self-awareness and self-regulation of their thinking, feelings and behaviours, and our analysis suggests students perceived these processes underpinned the effect of mindfulness on academic performance

\section{Conclusion}

Differences in students' psychological distress and study habits may determine the differing initial impact of mindfulness on academic performance.

\section{Details of contributors}

SB and JG had the idea for the study and planned it. SB led the study with support from JG, JCF and BV. SB and SC analysed the interview data. GD and PG facilitated the research and all authors reviewed and commented on the manuscript.

\section{Conflict of Interest}

The authors declare no conflict of interest

\section{Acknowledgements:}

We would like to thank all student participants in the study and Elizbeth English for delivering the mindfulness course. The first author would like to thank Aude Bicquelet, Sveta Mayer, Denis Mareschal, Iroise Dummontheil, Sue Whiting and Cathy Rogers, for their input and facilitation of the research project as well as acknowledge the help and support of Emily Pyle, Yaobin Tong, Beatrice Tourot and most especially Chizuru Kobayashi. 


\section{A follow-up study to a randomised control trial to investigate the perceived impact of mindfulness on academic performance in university students}

\section{Introduction}

In the context of secular mindfulness-based interventions, mind-fulness is defined as purposefully directing attention on a specific target, such as the sensation of breathing, or one's present moment thoughts and emotions whilst maintaining an attitude of nonjudgement and acceptance towards oneself (Kabat-Zinn, 2009). Mindfulness is considered a state, but by engaging in regular mindfulness meditation, an individual is said to develop greater trait-level mindfulness (Williams \& Kabat-Zinn, 2013).

Mindfulness has been shown to promote well-being and men- tal health in the general population, and numerous systematic reviews and meta-analyses have evidenced this (de Abreu Costa, de Oliveira, Tatton-Ramos, Manfro, \& Salum, 2019; Goldberg et al., 2018; Sevilla-Llewellyn-Jones, Santesteban-Echarri, Pryor McGorry, \& AlvarezJimenez, 2018; Tomlinson, Yousaf, Vitters $\varnothing$, \& Jones, 2018; Weare \& Huppert, 2019). Mindfulness has also been shown to have beneficial effects for reducing stress and anxiety in the workplace (Bartlett et al., 2019). Mindfulness training is increasingly being offered in universities to promote well-being (MFS, 2018). The Mindful Student Study (MSS), the largest mindfulness randomised control trial (RCT) with university students, evidences the moderate effects of mindfulness for reducing psychological dis- tress in university students (Galante et al., 2018) which concords with the results of recent systematic reviews and meta-analyses (Breedvelt et al., 2019; Dawson et al., 2019). However, whilst aca- demic performance, indicated by examination results, improved for some students in the mindfulness intervention group, it decreased for others (see Table 1) in comparison with the control group (Galante et al., 2018).

Whilst the extant cognitive psychology and education research literature provides some preliminary indication that mindfulness may support academic performance in university (Mrazek et al., 2013a; Mrazek et al., 2013b) and secondary school students (Bennett \& Dorjee, 2016; Klingbeil et al., 2017; Weare \& Huppert, 2019), there is a dearth of literature on theoretical formulations of how mindfulness could impact academic performance. Furthermore, there appears to be no previous research that addresses how mindfulness might have different effects on academic performance for different students. Given the growing appeal of mindfulness training in higher education, an understanding of what mediates and moderates the relationship between mindfulness and academic performance would be of value.

\section{How mindfulness could influence academic performance: models and evidence guiding our research questions}

Cognitive models of how mindfulness reduces psychological distress may help conceptualise how mindfulness impacts students' ability to perform academically. Numerous models of mindfulness exist (Malinowski, 2013; Shapiro et al., 2006; for a review of models see Quaglia et al., 2015). However, there appears to be consensus in the literature on two fundamental components of mindfulness: self-regulation of 
attention, and an attitudinal orientation towards acceptance and nonjudgment (Bishop et al., 2004; Cresswell, 2017). Researchers propose that reductions in psychological distress may be mediated by enhanced awareness of one's automatic thought processes and improved attentional control (Cresswell, 2017) resulting in i) recognising that ruminative and anxiety-provoking thoughts are not facts, ii) ignoring such thoughts and iii) selecting alternative thoughts (Williams, Penman \& Kabat-Zinn, 2011).

The cognitive models of mindfulness suggest at least three possible ways in which mindfulness training might support academic performance. Firstly, by improving regulation of attention,--mindfulness training enables students to sustain attention for longer periods and be less succeptible to distractions (Jain et al., 2007) which might enhance learning and examination performance.. Secondly, enhanced awareness of thought processes, may support meta-cognition (Hacker, Dunlosky \& Graesser, 2009) enabling students to better calibrate their comprehension and memory, and therefore self-regulate their learning (Winne, 2017). Thirdly, mindfulness training by reducing students' propensity to pay attention to distressing thoughts and ruminate (Deyo, Wilson, Ong \& Koopman, 2009) serves to make working memory more available for learning and performing academically as predicted by Attentional Control Theory (Derakshan \& Eysenck, 2009).

These theory-based proposals are partially supported by empirical data. For instance, mindfulness training improves measures of attention in the laboratory (MacLean et al., 2010; Ostafin, Robinson \& Meir 2015) and in naturalistic settings (Jain et al., 2007; Jensen et al., 2012; Jha., et al, 2015). Attention has not been investigated as a factor in academic performance in university students, but college students with attention deficits perform less well than their peers (Weyandt et al., 2013) which suggests attention is relevant to academic performance, and mindfulness could improve academic performance in those with attention deficits. In regard to mindfulness improving metacognition, no work appears to have been done with university students, but positive findings with children (Vickery \& Dorjee, 2016) and adolescents (Sanger \& Dorge, 2016) are reported. Qualitative research describes university students perceiving mindfulness improving awareness of their thought processes, which some felt helped them to concentrate better and thus be more academically productive (Kerrigan et al., 2017).

The suggestion that mindfulness frees up working memory by reducing attention to distressing thoughts is supported by research showing reduced ruminative and anxious thoughts (Gu et al., 2015) and improved working memory function (Jha et al., 2015; Jensen et al., 2012; Zeiden et al., 2010) following mindfulness training. Positive associations between improvements in working memory and academic performance have been reported in children (Alloway \& Alloway 2010). In university students Mrazek et al.(2013) found that mindfulness training led to reductions in mindwandering and improvements in working memory and reading comprehension indicating a possible mechanism through which mindfulness positively impacts academic performance. For students who scored highly on mind-wandering before mindfulness training, their improvement in reading comprehension and working memory was mediated by reduced mind-wandering (Mrazek et al., 2013). Other ways in which mindfulness has been shown to affect cognitive skills which could also have 
a positive impact on academic performance include improvements in insight problemsolving (Ostafin \& Kassman, 2012), memory (Bonamo, Legerski \& Thomas, 2014) and creativity (Ding et al., 2014).

Two previous qualitative studies explored university students' experience of mindfulness (Hjeltnes et al., 2015; Kerrigan et al., 2017). However, these studies did not specifically capture students' perceptions of how mindfulness affected their academic performance although mindfulness was inferred as being indirectly helpful. Kerrigan et al. (2017) found mindfulness reduced stress, anxiety and improved coping skills as well increased students' productivity and promoted a healthier relationship to studying by helping them procrastinate less and having greater self-efficacy for handling stress. Hjeltnes et al. (2015), whose participants self-identified as having academic evaluation anxiety, felt mindfulness reduced distractions from anxious thoughts as well as helped them to shift away from avoidance behaviours and experience greater enjoyment whilst learning. In neither study was there any indication that mindfulness might have an adverse effect on academic performance.

Given the current research landscape, this qualitative research was undertaken as a follow-up study to the Mindful Student Study RCT (Galante et al., 2018). The aims were to explore the extent to which mindfulness might have been perceived to have a positive or negative impact on students' academic performance, and to better understand individual differences in response to mindfulness. This study captures the experience of six Mindful Student Study RCT participants and offers a student-voiced and nuanced interpretation of some of the RCT results (see Table 1). This study also aims to draw on existing cognitive models of mindfulness as well as our findings, to further the understanding of relationships between mindfulness and academic performance in university students and to pave the way for future studies to look at causal relationships in more depth. The research question that guided the study was what are students' perceptions of the impact of the mindfulness training on their academic performance? Our findings were subsequently interpreted and linked with previous evidence to help gain an understanding of how mindfulness interacted with academic performance in the students.

\section{Methods}

\section{Participants}

Six university undergraduates (two females; age range 19-24; five white British and one international student of multiple ethnicity) were interviewed between May-August having undertaken in the preceding academic year an eight week mindfulness programme as part of the Mindfulnes Student Study. The characteristics of the students are shown in Table 2.

\section{Procedures}

The sampling frame was derived from the master list of students who had been randomly allocated to the mindfulness course in the RCT. Our intention was to capture a range of different narratives of the effect of mindfulness training on academic performance as indicated by examination results. It seemed reasonable to expect that narratives of mindfulness having a beneficial impact on academic performance would be more likely among students who performed highly in their exams and that conversely, narratives of mindfulness having an adverse impact might be more likely among those whose performance was lower. Therefore, purposeful sampling 
(Denscombe, 2014) was used to recruit both low and high performing students. Students who achieved first-class, or upper second-class grades (2.1), the two highest undergraduate classifications, were designated as high performing and those with lower second-class grades (2.2), third-class grades, or failures were designated as low performing. The boundary between upper second-class (2.1) and lower-second class (2.2) grades was used to distinguish high and low performing students because securing an upper second classification (2.1) degree is perceived by students as very important as many graduate employment and further study opportunities require a 2.1.

Students were initially sent an email inviting them to express interest in participating in the interview. As an incentive to participate, gift vouchers worth 15 British pounds with an online retailer were offered. Students who responded were sent a participant information sheet, a consent form to sign and a range of available interview slots. Indepth interviews were chosen as they provide data that can be used to help identify relationships, develop new theories and follow up unexpected results (Tuckman in Cohen, Manion \& Morison, 2011, p.11). Semi-structured interviews were used as they are sufficiently directive to ensure topics relevant to the research question were covered in each of the interviews. Equally they offer the flexibility to explore and probe individual responses (Newby, 2010, p.343). The interview schedule devised had six open-ended questions and introductory and closing comments and is shown in Table 3. The interviews were approximately one and a half hours long, audio recorded and transcribed verbatim with the transcripts subsequently used for data analysis. The research was conducted in accordance with the British Educational Research Association's Ethical Guidelines (BERA, 2011) and qualitative research best practice guidelines (Elliot, Fischer, Rennie, 1999; O'Brien et al., 2014; Wu et al., 2017). Approval for the study was granted by Psychology Research Ethics Committee of the university where the study was conducted.

To minimize unrecognised researcher bias influencing the research process (Finlay, 2016 ; 2002), we engaged with reflexivity throughout the study both as a construct and activity (Shaw, 2010) to examine how our subjectivity might be impacting the research. The study was conducted primarily by the first author, a qualitative researcher with assistance with coding from the third author. The last author led the Mindful Student Study RCT and the second author is a qualitative researcher and psychologist with experience of mindfulness research. The other coauthors were involved in facilitating the study and reviewing and commenting on drafts of this article.

The first author is familiar with mindfulness practice but was not involved in the Mindful Student Study RCT and is not a mindfulness teacher. In part, this may have served to reduce the potential for research bias due to allegiance to mindfulness training (Dragioti, Dimoliatis \& Evangelou, 2015). The first works as a tutor and academic advisor at a different university to that attended by the participants. This ensured he had familiarity with students' study experiences whilst possibly facilitating students speaking candidly, as fear of negative evaluations, particularly among the lower performing students, may have been reduced by speaking to an outsider.

The first author noted that all six participants expressed a sense of appreciation at having been able to attend the Mindful Student Study and although he had not been involved in delivering MSS, he felt this appreciation partly directed at him in the interview. To not let positive feelings between researcher and interviewee unduly influence objectivity and criticality (Berger, 2015) the first author sought to remain 
aware of his own emotions and transference during the interviews (Gemignani, 2011). $\mathrm{He}$ also maintained clear boundaries, ensuring that the interview schedule was adhered to and that all interviews did not run over 90 minutes.Analysis of data

To capture nuanced and rich descriptions of students' experiences of mindfulness and their perceptions of how it impacted their ability to perform academically an interpretivist research paradigm using qualitative methods was appropriate (Thorne, 2016). This was achieved by applying thematic analysis to the entirety of interview transcripts using the six steps outlined in Braun and Clarke (2006). A reason for using thematic analysis is its independence of any particular theory and epistemology (Braun \& Clarke, 2006) and thus allows for detailed and complex accounts of the interview data free of pre-existing assumptions, concepts and models. By reading through the transcripts closely, identifiable patterns in students' responses were categorised into a list of primary codes. The coding process was undertaken by the first and third author working independently where it was agreed a code represented things that were said in common across the dataset and related to the research questions, but which were sufficiently distinctive to be divergent from another code. To ensure rigour both coders checked the other's list of codes and their corresponding interview segments. Through discussion and consensus, a condensed list of secondary codes was then created. Subsequently by reading the interview segments relating to each secondary code and repeatedly searching for relationships between codes, basic themes were identified. This was done using predominantly an inductive process (Braun \& Clarke, 2006). Through a process of iteration, the list of basic themes was reduced to a list of organising and then finally global themes. This process involved creating visual representations of the various levels of themes called thematic networks (AttrideStirling, 2001: Braun \& Clarke, 2006). The research question, together with findings from previous research, was used to interpret the patterns in the thematic network. A final report of the findings was sent to participants for comment for participant validation.

\section{Results}

Three lower and three higher performing students were interviewed (see Table 2). The initially created primary codes were condensed into a list of a secondary codes from which basic, organising and global themes were derived. Table 4 shows the correspondencse between secondary codes and participant statements as well as how these relate to the three global themes. Table 5 summarises the participants' perceptions of the influences of mindfulness on their academic performance.

\section{1) Positive influences of mindfulness on academic performance}

Five students perceived mindfulness as having improved their ability to study and perform academically. The students' perceptions of the positive impact mindfulness had on their academic performance fell into two separate organising themes: positive indirect influences, which five students described, and positive direct influences which three students described (see thematic network in Figure 1 and Table 5).

\section{Indirect positive influences of mindfulness on academic performance}

An 'indirect' influence refers to a change in a factor that is not directly tasked by examinations but influences other factors that are directly tasked by examinations such as quantity of subject knowledge, memory skills, comprehension, informationprocessing and critical-thinking skills. The student narratives revealed four types of positive indirect influences now described in decreasing order of emphasis. 
Five students spoke of their perception that mindfulness had reduced the distress of exams, deadlines and tutorials:

S3: It helped me as a person cope with the stress of the deadlines...it made the whole term a lot less stressful ...including revising

The second most emphasised indirect positive influence was enhanced energy and stamina for studying which three students talked about as illustrated by S4:

S4: I found the meditation particularly helpful when it came to studying. The more I practised the more energised and up to studying I felt if I had a difficult day

The third indirect positive influence was greater enjoyment of studying which was implied by two students and mentioned explicitly by another two students:

S6: [mindfulness] just made me relax a lot more and enjoy my subject a lot more... I like going to lectures now and I like being there

The fourth indirect positive influence was reduced procrastination which was implied by one student and mentioned explicitly by S3:

S3: I've always had a big problem with procrastinating which led to stress... I didn't have that so much when I was doing the mindfulness

\section{Direct positive influences of mindfulness on academic performance}

A direct influence refers to a change in a factor that is essential for performing well in exams. Four students (two high and two lower performing students) spoke of such influences which have been grouped into three basic themes (Figure 1). Enhanced intellectual creativity, integrative thinking and insight is the first basic theme and constituted the most prevalent perceived positive direct influences of mindfulness on academic performance for S2, S3 and S4 with the latter explaining:

S4: Because [due to mindfulness] I've been more reflective, have a greater deal of awareness and thought about things a bit more... I was able to come up with...more original ideas...it...helped with my creativity... to think outside the box and think of different ways you can link in different parts of the course to an essay...mindfulness sort of opens up my mind... allowing my brain to think creatively, like access memories and come up with ideas...look at things freshly

S4 also underscored how she felt mindfulness supported her ability to integrate different pieces of information particularly when working with abstract concepts and gain insights when problem-solving:

S4: that part of our brain that, sort of, takes an abstract concept and works with it...I'm able to switch it on with mindfulness..., I wouldn't look at a maths question and immediately think of a method to solve it, I would sort of just play with the numbers and the solution would ... come by itself to me...so, rather than looking at something and thinking 'right...these are the tools to fix it'... I 
found mindfulness helped me look at questions and then have abstract ideas about ways in which I could link things I already knew to solve that question

Enhanced analytical thinking was the second, less emphasised basic theme mentioned by S4, S3 and S2:

S2: I have deeper thoughts about my studies...and having a greater deal of awareness, I was able to come up with more analytical points

S3: [mindfulness] helped me be freer and ...be willing to take intellectual risks... also be self-confident in my analysis

Enhanced memory was a final basic theme. This was described as resulting from better elaborative and associative encoding of study material and thus better processing and subsequent retrieval of information. Greater enjoyment and interest in the study material was also felt to have been the result of mindfulness practice which in turn supported memory:

S4: Mindfulness, helped me look at things freshly and make connections between abstract things which is really the way I remember things best by linking in my studying... mindfulness has helped me avoid doing things by rote... it helped with my memory in exams...I would use the mindfulness in the exam, which I found really reduced my anxiety level and helped with the memory

S6: [as a result of mindfulness] l've just enjoyed doing what l'm doing ... like wow, that's really interesting and that helps me remember it more cos like you actually care about what you're doing

\section{2) Negative influences of mindfulness on academic performance}

One low performing student felt mindfulness had initially had a negative impact on his academic performance. "For me actually, I think it [mindfulness meditation] made me study less" he explained elaborating that reduced study adversely affected his academic performance:

S6: It [mindfulness] would have an impact on my grades cos, I didn't work so intensely. Cos I would feel, I'm not enjoying this, this is becoming a burden, I'm going to stop and do something else... which has been really been great for me, but probably not great for my grades! But yeah it has stopped me from like... what I would have done is just cram, and just try and revise and like go to the library everyday like everyone is... but then instead I was just like sometimes, well... I just go for a walk instead so, yeah...

The student, who was being interviewed one year after he had taken part in the mindfulness course described himself to be "in a process" whereby as a result of the mindfulness-induced realisation of how distressing he found "really cramming" (that is studying intensely without breaks under significant psychological pressure in order to cover a considerable amount of study material in a very limited time frame) he was now cramming much less. He reported enjoying his studies more and felt confident his grades would improve this year and next year. He also implied mindfulness was helping him to focus better in lectures and be more intellectually confident in the one- 
to-one supervision meetings with his tutor. Thus, although he felt that mindfulness initially had an adverse impact on his academic performance, in the longer term he felt it was helping him.

\section{3) Enhanced self-awareness and self-regulation}

The third global theme which emerged from the interview data of all participants was enhanced self-awareness and self-regulation. The theme compromises three organising themes relating to self-awareness and self-regulation of i) thoughts, ii) emotions and iii) behaviours.

\section{Self-awareness and self-regulation of thoughts}

Participants described an enhanced ability to notice and observe their thought processes and as a consequence modify, or ignore thoughts. This was perceived to have an impact on both thinking for academic purposes and thinking related to the self:

S4: Mindfulness made me better able to detach from my thoughts. I was able to see my thought patterns were abstract things and I could choose whether, or not I went with them

S1: I'm able to recognise thoughts and perceive them much better than before. When I'm stressed about something I realise that "oh, I'm thinking this again" and change track as it were...mindfulness gives me a sense of control and choice and that reduces my stress

\section{Self-awareness and self-regulation of emotions}

Students also perceived gaining improved awareness and capacity to regulate emotions:

S2: Mindfulness makes you more sensitised to your emotional state. I am more attuned to what is going on for me and this greater sensitivity means I'm better able look after myself emotionally, like remind myself of what is really important in life and so feel less stressed and anxious about exams.

S3: Mindfulness made revising less stressful... it made it less of an issue with less anxiety

S5: I am more aware of my sensory experiences and more keen on trying to give myself space to experience the world around me

\section{Self-awareness and self-regulation of behaviours}

The final organising theme captures students' perceptions that as a result of mindfulness they were more aware of, and better able to, change their study and lifestyle behaviours:

S3: After mindfulness, I started doing more physical exercise and recognised l'd been going out quite a lot in the previous terms and drinking a lot of alcohol, so I completely cut back on my alcohol consumption 
S4: Mindfulness make me more aware... it definitely helped me to take study breaks... it helped me to treat myself in a way that I would treat someone else. It helped me stop studying to the point of exhaustion and with other things like remembering to feed myself and do exercise

S2: Mindfulness made me more aware that in the grand scheme of things... it's more important to support other people than it is to just work constantly without thinking about what other people are going through.,, so it's worth spending time...supporting someone else if that's needed. Mindfulness made me take a step back... I do think that it did significantly improve my selfawareness and empathy

Students indicated that such changes in behavior reduced their distress and was perceived to have a positive impact on their ability to study:

S4: Mindfulness helped me take a step back, look at myself critically, make changes, which helped with my studies

The notion that mindfulness enhances self-awareness and self-regulation over anxious thoughts and emotions, unhealthy lifestyles and unproductive study behaviours which in turn was perceived to impact academic performance is represented in the thematic network map in Figure 2.

\section{Discussion}

Our findings provide a response to the research question regarding students' perceptions of the impact of mindfulness on academic performance (see Table 5). Whilst our qualitative research cannot prove any causal relationship between mindfulness and academic performance, the findings, along with previous research, shine light on the question of how mindfulness interacts with academic performance, allowing us to offer some speculative hypotheses for future research.

Perceived direct positive influence of mindfulness on academic performance

Students' perceptions of the direct positive influence of mindfulness on academic performance by enhancing creativity, integrative-thinking, analysis and insight, as well as memory resonates both with higher education research on the significance of these abilities for academic performance (Huber et al., 2017; Krathwohl, 2002; LopezChavez \& Shepherd 2010) and with studies demonstrating mindfulness improves creativity (Ding, Ding, Tang \& Posner, 2014; Lebuda, Zabelina \& Karwowski, 2016) insight (Ostafin \& Kassman, 2012; Ren et al., 2011) and memory (Bonamo et al., 2015, Mzarek et al., 2013). The perceived positive direct influences of mindfulness on academic performance could result from students' enhanced awareness of their thought processes during intellectual activity and their ability to regulate their thinking. Greater meta-cognitive awareness and internally focused attention may give students greater capacity to notice and switch attention to thoughts with weak neural activation that are non-dominant, non-obvious and novel, and in so doing support intellectual insight in line with the cognitive mechanism for insight proposed by Kounios and Beeman (2014) and Kunios et al. (2006). Similarly, meta-cognitive awareness and internally focused attention may facilitate recognising associations between ideas which may support integrative-thinking and creativity. Mindfulness might support analytic thinking by reducing distractions and enhancing attention to the information to 
be analysed. Improved capacity to notice and choose between different thoughts could promote cognitive flexibility which might promote analytical-thinking. The same mechanisms may also support memory by enabling a greater degree of processing of information to be memorised leading to improved encoding into, and subsequent retrieval from, memory storage in accordance with levels of processing theory of memory (Craik,2002).

\section{Perceived indirect positive influence of mindfulness on academic performance}

The perceived indirect positive influences of mindfulness on academic performance are congruent with previous research. Students' perceptions that reductions in procrastination and distress promoted their academic performance, whilst intuitive, are equally supported by meta-analytic data of studies with university students (Richardson, Abraham \& Bond, 2012). The attenuating effect of mindfulness on procrastination students described corresponds with narratives reported in Kerrigan et al. (2017). Similarly, that mindfulness reduces distress is consistent with qualitative research on university students' experience of mindfulness by Kerrigan et al. (2017) and Hjeltnes et al. (2015), as well as with data from the Mindful Student study RCT (Galante et al. 2018), and recent meta-analytic studies (Breedvelt et al., 2019; Dawson et al., in press)

One possible way in which mindfulness may indirectly support academic performance is that the reduction mindfulness appears to cause in distressing-causing thoughts changes how working memory capacity is allocated. According to attentional control theory, ACT (Derakshan \& Eysenck, 2009), distressing thoughts reduce cognitive resources (working memory and attentional control) available for processing information and attending to complex tasks especially in performance situations. Thus, a reduction in distressing-causing thoughts could allow for a greater allocation of working memory to be deployed on tasks directly relevant to academic performance and thus enhance academic performance.

The themes of enhanced sense of energy for study and enjoyment may be related to students enhanced ability to notice thoughts that generate a sense of threat such as self-critical evaluations and negative scenarios of the future, and either ignoring these thoughts, or generating alternative ones. Changes in how students evaluate themselves and their perspective on academic success may lead to less fear-of-failure (Ekert et al., 2016) or a different relationship to thoughts of failure such that students identify the thoughts as thoughts, rather than as facts. Fear-of-failure is a recognised contributor to procrastination in students (Ekert et al., 2016.) and a reduction in fearof-failure may reduce threat based extrinsic motivation for study and allow for greater intrinsic motivation with a concomitant sense of increased energy, and enjoyment for studying (Deci \& Ryan, 2008).

\section{Individual variation in perceived impact of mindfulness on academic performance}

If increased self-awareness and self-regulation serve as the underlying mechanism by which mindfulness influences academic performance, they must account for both improvements and possible decrements in academic performance. In the case of S6, increased self-awareness made him more aware of the distress associated with studying excessively hard. This led to self-regulatory changes in i) thinking "I'm not enjoying this, I'm going to stop", ii) behaviour "what I would have done is just cram, 
instead...sometimes... I just went for a walk", and ultimately iii) emotions in that he felt less distress. However, these changes were accompanied by a perceived decrease in his academic performance. S6 was the only one of the three low performing students interviewed (see Table 2) who described mindfulness having a negative influence on academic performance. It is worth noting that S6 was in his second year when he learnt mindfulness. One can speculate that students' motivation to perform academically may be less strong in the second year compared to students in their final year, as the consequences of poor exam performance are less significant than in the final year when they determine degree classification. It is possible that being a second year student might have facilitated S6 heeding his mindfulness-induced inclination to take time away from his studies which, had S6 been in his final year, he might have resisted more eagerly and continued to "cram", that is study intensely under very considerable time and psychological pressure. $\$ 6$ emphasised practising mindfulness as being an on-going "process" which he felt would eventually result in helping him perform better academically. Students practising mindfulness could be conceived as a process of decompression a term from military psychology (Hacker Hughes et al., 2008), which describes the process of psychological readjustment required following experiences of excessive distress. Whether mindfulness has a perceived positive or negative initial impact on academic performance could be determined by two factors. Firstly, a student's state of distress prior to mindfulness training. Secondly, the extent to which this distress is related to stress-inducing study habits such as cramming. For students who rely extensively on cramming, the readjustment that mindfulness elicits reduces their engagement with the cramming study habit they rely on. Consequently, until the student develops alternative, less stressful ways of studying, which may take time, there is a drop in academic performance. However, for students who have effective and less stress inducing study habits, they do not become aware of the need to disengage from their current study habits in order to reduce distress when academic performance they start mindfulness training, and experience exclusively a positive impact on their academic performance.

\section{Perceptions of enhanced self-awareness and self-regulation and correspondence to cognitive neuropsychology research on mindfulness}

The themes of awareness and self-regulation of thinking, feeling and behaviour also have resonance in the literature. Mindfulness has previously been reported to enhance meta-cognitive awareness (Cresswell, 2017; Jankowski \& Holas, 2014) and is also theorised to improve cognitive and emotional regulation skills (for a review see Creswell, 2017). Previous research has demonstrated the importance of metacognition for supporting academic performance and self-regulation strategies for learning (Winne, 2018) which in turn are associated with academic self-efficacy (Honnicke \& Broadbent, 2015). Both self-regulation of learning and academic selfefficacy correlate positively with academic performance (Richard, Abraham \& Bond, 2012). The students' perception that mindfulness enhanced self-awareness and selfregulation of thoughts, feelings and behaviours and that this led to changes which supported their academic performance bears similarity to the proposed mechanism of action of mindfulness based cognitive therapy (Segal, Williams \& Teasdale, 2018). The putative mechanism of action is that mindfulness leads to heightened metacognitive awareness which enables individuals to shift the way in which they relate to their day-to-day experiences from a "narrative" mode to an "experiential" mode (Farb et al., 2007; Tang, Hölzel \& Posner, 2015). The narrative mode is the default mode of the mind and is related to automatic thoughts that can be self- 
evaluative and judgmental in nature (Segal et al., 2018). Whilst this likely has functional value (Raichle, 2015), mindfulness researchers propose the default mode can also be responsible for cycles of negative self-evaluations and anxious thoughts caused by constant focusing on the discrepancy between reality and a desiredalternative state (Sipe \& Eisendraft, 2012; Segal et al., 2018). In contrast, the experiential mode is characterised by an awareness and acceptance without evaluation or judgement of present moment thoughts and emotions (Tang, Hölzel \& Posner, 2015). This enables individuals to be more disengaged observers of their own selves which fosters a greater sense of choice and regulation over thoughts, emotions and behaviours with beneficial consequences for wellbeing, and according to the perceptions of five of the students in this study findings, academic performance. Being in the experiential mode may facilitate experiences of flow (Dietrich, 2015), the highly attentive state of conscious in which one is deeply and pleasurably engrossed in a task and performs it to the best of one's ability (Csikszentmihalyi, 2014). The student narratives describing the increased awareness of, and regulation of their thoughts, feeling and behaviours could be interpreted as offering first-hand phenomenological accounts of a relative decrease in default narrative mode and increase in experiential mode activity consequent to mindfulness and the impact this has on academic performance. A novel contribution of this study is to explore the perceived impact of this shift on university students' academic performance rather than on mental health, which has been the focus of much of mindfulness research to date.

\section{Limitations}

Although our analysis of the student narratives has been used to suggest a possible relationship between mindfulness and academic performance, this exploratory qualitative study cannot demonstrate causal effects. Furthermore, the results rest on accepting the validity of students' perceptions that mindfulness meditation elicited the effects they described. However, the changes the students reported may be due to other factors, such as the psychoeducational components of attending the Mindfulness Student Study mindfulness classes, group dynamics or expectations about mindfulness. An additional limitation is that the individual student accounts cannot generalise to the rest of the students in the Mindfulness Student Study or university students more broadly. The small number of participants in this study selfselected and there may therefore be sample characteristics that differentiate the students in this study. It would have been beneficial had more students volunteered for the study, especially lower attainers, but efforts to recruit a larger number of participants were unsuccessful. A further issue is the possibil- ity of confounding variables in relation to the participants' subject and year of study, whereby all of the low-attainers studied Science and all of the high attainers studied Humanities or Social Sciences. Finally, the interview data were collected at only one point in time and thus dependent on participants remembering experiences that had occurred up to a year in the past, which will have increased the risk of recall bias. The above points notwithstanding, the congruency between the students' descriptions of their experiences and previous research on the effects of mind-fulness means the active role of mindfulness in producing the perceived effects the students described seems worthy of consideration and further research.

\section{Conclusions an implications for furture research and practice}


The six narratives of students in this study indicate that different stu- dents have differing perceptions of the impact of mindfulness on academic performance. Our qualitative study aligns with the RCT data in Galante et al. (2018), which revealed mixed effects of mindfulness on academic performance. The limited number of participants in our study would ordinarily preclude drawing conclusions regarding the applicability of our findings beyond the individuals interviewed. However, the correspondence between the mixed effects of mind-fulness revealed in the RCT data and the differing narratives among our participants regarding how mindfulness was perceived to impact academic performance suggest that these patterns of individual dif- ference in how mindfulness is felt to impact academic performance may apply more broadly to university students.

This is of relevance to counsellors and psychotherapists within institutions of higher education or working in public or private healthcare settings with clients who are students. The proportion of university students with a diagnosed mental illness is increasing (Brown, 2016), and increasing numbers of students are presenting to university counselling services (Brown, 2016). Many of these students may be seeking to alleviate concerns about their academic performance and improve it (McKenzie, Murray, Murray, \& Richelieu, 2015). Mindfulness courses are increasingly being offered in universities (MFS, 2018). Furthermore, mindfulness practice is a core component of several third-wave therapies such as dialectical behaviour therapy (DBT; Childs-Fegredo \& Fellin, 2018), mindfulness-based stress reduction, MBCT (Segal et al., 2018), mindful self-compassion (Neff \& Germer, 2013) and compassion-focused therapy (CFT; Gilbert, 2010), which are increasingly accessible to nonclinical populations including university students (Kirby, 2016; Wilson, Mackintosh, Power, \& Chan, 2019).

Our study adds to the existing empirical research indicating that the majority of higher education students who access mindfulness training will likely experience it as beneficial for psychological distress. Furthermore, the student narratives describing enhanced awareness and self-regulation of thoughts, feeling and behaviours (Figure 2) following mindfulness training offers counsellors and psychotherapists a potentially useful conceptual model for understanding how mindfulness training might support wellbeing and academic performance. Such a model may be particularly helpful when discussing mindfulness and issues relating to emotional dysregulation, which is an increasingly common feature of presentations among young adults accessing mental health services (Gaynor \& Gordon, 2019). Finally, and most significantly, our study raises awareness among clinicians of the possibility that whilst for many students the beneficial effect of mindfulness on levels of distress will likely be matched by a perception that mindfulness enhances their academic performance, for some students the inverse may occur. Awareness that not all students may experience mindfulness training as immediately supportive of their academic performance is potentially a helpful insight for counsellors, university wellbeing services and students themselves when considering if, and when, to access mindfulness training.

The tentatively suggested applicability of our findings needs to be scrutinised by more substantial research into how mindfulness and academic performance interact among students in higher education. Future studies would benefit from larger and less heterogeneous sample sizes and could attempt to explore whether factors such 
as baseline mental health, working memory capacity, prior attainment levels, study habits (e.g. 'cramming') and timing of the mindfulness training with respect to the examinations can account for variation in students' experience of the impact of mindfulness on their academic performance.

Future research could also investigate whether the influences of mindfulness training can be captured using outcome measures other than self-report. Determining whether self-reported behavioural and psychological changes correspond with changes in neurobiological measures could provide useful insights into possible neurobiological mechanisms that underpin any changes in functioning. Such studies would benefit from employing active control groups in order to isolate the specific effect of mindfulness. The lack of active control groups in most research studies on mindfulness to date, as highlighted in the meta-analysis by Breedvelt et al. (2019), means that whether mindfulness is any more or less beneficial to academic performance, or wellbeing, than any other disciplined practice, such as a sport, or artistic activity remains an open question

\section{Conflicts of interest and funding}

We declare no conflict of interest and no specific support from any organisation for the submitted work; no specific financial relationships with any organisation that might have an interest in the submitted work in the previous three years and no other relationships or activities that could appear to have influenced the submitted work.

\section{Ethical approval and informed consent}

Informed consent was obtained from all individual participants included in the study and all procedures performed in studies involving human participants were in accordance with the ethical standards of the university's Pyschology Research Ethics Committee, (application number 2017.003) and with the 1964 Helsinki declaration and its later amendments or comparable ethical standards.

\section{References}

Alloway, T. P., \& Alloway, R. G. (2010). Investigating the predictive roles of working memory and IQ in academic attainment. Journal of experimental child psychology, 106(1), 20-29. doi: 10.1016/j.jecp.2009.11.003

Attride-Stirling, J. (2001). Thematic networks: an analytic tool for qualitative research. Qualitative Research, 1(3), 385-405. doi: 10.1177/146879410100100307

Bamber, M. D., \& Morpeth, E. (2019). Effects of mindfulness meditation on college student anxiety: A meta-analysis. Mindfulness, 10(2), 203-214. doi: 10.1007/s12671018-0965-5

Bartlett, L., Martin, A., Neil, A. L., Memish, K., Otahal, P., Kilpatrick, M., \& Sanderson, K. (2019). A systematic review and meta-analysis of workplace 
mindfulness training randomized controlled trials. Journal of occupational health psychology, 24(1), 108. doi: 10.1037/ocp0000146Bennett, K., \& Dorjee, D. (2016). The impact of a mindfulness-based stress reduction course (MBSR) on well-being and academic attainment of sixth-form students. Mindfulness, 7(1), 105-114. doi: $10.1007 / \mathrm{s} 12671-015-0430-7$

BERA, British Educational Research Association. (n.d.). Ethical Guidelines for Educational Research. Available at https://www.bera.ac.uk/wpcontent/uploads/2014/02/BERA-Ethical-Guidelines-2011.pdf?noredirect=1 [Accessed on 03/08/2019]

Berger, R. (2015). Now I see it, now I don't: Researcher's position and reflexivity in qualitative research. Qualitative research, 15(2), 219-234. doi:

$10.1177 / 1468794112468475$

Bishop, S. R., Lau, M., Shapiro, S., Carlson, L., Anderson, N. D., Carmody, J., \& Devins, G. (2004). Mindfulness: A proposed operational definition. Clinical Psychology: Science and Practice, 11(3), 230-241. doi: 10.1093/clipsy/bph077

Bonamo, K. K., Legerski, J. P., \& Thomas, K. B. (2015). The influence of a brief mindfulness exercise on encoding of novel words in female college students. Mindfulness, 6(3), 535-544. doi: 10.1007/s12671-014-0285-3

Braun, V., \& Clarke, V. (2006). Using thematic analysis in psychology. Qualitative Research in Psychology, 3(2), 77-101. doi: 10.1191/1478088706qp063oa

Breedvelt, J., Amanvermez, Y., Harrer, M., Karyotaki, E., Gilbody, S., Bockting, C. L., ... \& Ebert, D. D. (2019). The effects of meditation, yoga and mindfulness on depression, anxiety and stress in tertiary education students: A metaanalysis. Frontiers in psychiatry, 10, 193. doi: 10.3389/fpsyt.2019.00193Brewer, J. A., Worhunsky, P. D., Gray, J. R., Tang, Y. Y., Weber, J., \& Kober, H. (2011). Meditation experience is associated with differences in default mode network activity and connectivity. Proceedings of the National Academy of Sciences, 108(50), 2025420259. doi: $10.1073 /$ pnas.1112029108

Brown KW, Creswell JD, Ryan RM, eds. (2015). Handbook of Mindfulness: Theory, Research, and Practice. New York: Guilford Publications

Brown P (2016) The Invisible Problem? Improving students' mental health. HEPI Report 88. Higher Education Policy Institute (HEPI) Available at https://www.hepi.ac.uk/2016/09/22/3592/ [Accessed on 04/11/19]

Childs-Fegredo, J., \& Fellin, L. (2018). 'Everyone should do it': Client experience of a 12-week dialectical behaviour therapy group programme-An interpretative phenomenological analysis. Counselling and Psychotherapy Research, 18(3), 319331. doi.org/10.1002/capr.12178

Cohen, L., Manion, L., \& Morrison, K. (2011). Research methods in education (5 th). London: Routledge.

Conley, C. S., Durlak, J. A., \& Kirsch, A. C. (2015). A meta-analysis of universal mental health prevention programs for higher education students. Prevention Science, 16(4), 487-507. 
Craik, F. I. (2002). Levels of processing: Past, present... and future?. Memory, 10(56), 305-318. doi: 10.1080/09658210244000135

Creswell, J. D. (2017). Mindfulness Interventions. Annual Review of Psychology, 68(1), 491-516. doi: 10.1146/annurev-psych-042716-051139

Csikszentmihalyi, M. (2014). Toward a psychology of optimal experience. In Flow and the foundations of positive psychology (pp. 209-226). Springer, Dordrecht. doi:10.1007/978-94-017-9088-8_14

Dawson, A. F., Brown, W. W., Anderson, J., Datta, B., Donald, J. N., Hong, K., . . Galante, J. (In press). Mindfulness-based Interventions for University Students: A Systematic Review and Meta-analysis of Randomized Controlled Trials. Applied Psychology: Health and Well-Being.

de Abreu Costa, M., de Oliveira, G. S. D. A., Tatton-Ramos, T., Manfro, G. G., \& Salum, G. A. (2019). Anxiety and stress-related disorders and mindfulness-based interventions: a systematic review and multilevel meta-analysis and meta-regression of multiple outcomes. Mindfulness, 10(6), 996-1005. doi: 10.1007/s12671-018-1058-1Deci, E. L., \& Ryan, R. M. (2008). Facilitating optimal motivation and psychological well-being across life's domains. Canadian Psychology/Psychologie Canadienne, 49(1), 14-23. doi: org/10.1037/0708-5591.49.1.14

Denscombe, M. (2014). The good research guide: for small-scale social research projects. London: McGraw-Hill Education (UK).

Derakshan, N., \& Eysenck, M. W. (2009). Anxiety, processing efficiency, and cognitive performance: New developments from attentional control theory. European Psychologist, 14(2), 168-176. doi: 10.1027/1016-9040.14.2.168

Dietrich, A. (2015). Flow Experiences: From Mystery to Mechanism. In How Creativity Happens in the Brain (pp. 163-183). Palgrave Macmillian, London doi:10.1057/9781137501806_8

Ding, X., Tang, Y.-Y., Tang, R., \& Posner, M. I. (2014). Improving creativity performance by short-term meditation. Behavioral and Brain Functions, 10, 9. doi: 10.1186/1744-9081-10-9

Dragioti, E., Dimoliatis, I., \& Evangelou, E. (2015). Disclosure of researcher allegiance in meta-analyses and randomised controlled trials of psychotherapy: a systematic appraisal. British Medical Journal Open, 5(6), e007206. doi: 10.1136/bmjopen-2014-007206

Eckert, M., Ebert, D. D., Lehr, D., Sieland, B., \& Berking, M. (2016). Overcome procrastination: enhancing emotion regulation skills reduce procrastination. Learning and Individual Differences, 52, 10-18. doi.org/10.1016/j.lindif.2016.10.001

Farb, N. A., Segal, Z. V., Mayberg, H., Bean, J., McKeon, D., Fatima, Z., \& Anderson, A. K. (2007). Attending to the present: mindfulness meditation reveals distinct neural modes of self-reference. Social cognitive and affective neuroscience, 2(4), 313-322. doi: 10.1093/scan/nsm030 
Finlay, L. (2002). "Outing" the researcher: The provenance, process, and practice of reflexivity. Qualitative health research, 12(4), 531-545. doi:

$10.1177 / 104973202129120052$

Finlay, L. (2017). Championing “reflexivities”. Qualitative Psychology, 4(2), 120. doi: 10.1037/qup0000075

Galante, J., Dufour, G., Vainre, M., Wagner, A. P., Stochl, J., Benton, A., ... \& Jones, P. B. (2018). A mindfulness-based intervention to increase resilience to stress in university students (the Mindful Student Study): a pragmatic randomised controlled trial. The Lancet Public Health, 3(2), e72-e81. doi: 10.1016/S2468-2667(17)30231-1

Gaynor, K., \& Gordon, O. (2019). Cognitive Behavioural Therapy for Mild-to-Moderate Transdiagnostic Emotional Dysregulation. Journal of Contemporary Psychotherapy, 49(2), 71-77. doi.org/10.1007/s1087

Gemignani, M. (2011). Between researcher and researched: An introduction to countertransference in qualitative inquiry. Qualitative Inquiry, 17(8), 701-708. doi: $10.1177 / 1077800411415501$

Gilbert, P. (2010). An introduction to compassion focused therapy in cognitive behavior therapy. International Journal of Cognitive Therapy, 3(2), 97-112. doi.org/10.1521/ijct.2010.3.2.97

Goldberg, S. B., Tucker, R. P., Greene, P. A., Davidson, R. J., Wampold, B. E., Kearney, D. J., \& Simpson, T. L. (2018). Mindfulness-based interventions for psychiatric disorders: a systematic review and meta-analysis. Clinical psychology review, 59, 52-60. doi: 10.1016/j.cpr.2017.10.011Gu, J., Strauss, C., Bond, R., \& Cavanagh, K. (2015). How do mindfulness-based cognitive therapy and mindfulnessbased stress reduction improve mental health and wellbeing? A systematic review and meta-analysis of mediation studies. Clinical Psychology Review, 37(Supplement C), 1-12. doi: 10.1016/j.cpr.2015.01.006

Hacker, D. J., Dunlosky, J., \& Graesser, A. C. (Eds.). (2009). Handbook of metacognition in education. New York: Routledge.

Hacker Hughes, J. G., Earnshaw, N. M., Greenberg, N., Eldridge, R., Fear, N. T., French, C., ... \& Wessely, S. (2008). The use of psychological decompression in military operational environments. Military medicine, 173(6), 534-538. doi: 10.1007/978-3-319-66192-6_7

Hjeltnes, A., Binder, P. E., Moltu, C., \& Dundas, I. (2015). Facing the fear of failure: An explorative qualitative study of client experiences in a mindfulness-based stress reduction program for university students with academic evaluation anxiety. International journal of qualitative studies on health and well-being, 10(1), 27990. doi: 10.3402/qhw.v10.27990

Jain, S., Shapiro, S. L., Swanick, S., Roesch, S. C., Mills, P. J., Bell, I., \& Schwartz, G. E. (2007). A randomized controlled trial of mindfulness meditation versus relaxation training: effects on distress, positive states of mind, rumination, and 
distraction. Annals of behavioral medicine, 33(1), 11-21. doi: 10.1207/s15324796abm3301_2

Jensen, C. G., Vangkilde, S., Frokjaer, V., \& Hasselbalch, S. G. (2012). Mindfulness training affects attention-or is it attentional effort? Journal of Experimental Psychology: General, 141(1), 106. doi: 10.1037/a0024931

Jha, A. P., Morrison, A. B., Dainer-Best, J., Parker, S., Rostrup, N., \& Stanley, E. A. (2015). Minds "At Attention": Mindfulness Training Curbs Attentional Lapses in Military Cohorts. PLOS ONE, 10(2), e0116889. doi: 10.1371/journal.pone.0116889

Kabat-Zinn, J. (2009). Wherever you go, there you are: Mindfulness meditation in everyday life. London: Hachette UK.

Kerrigan, D., Chau, V., King, M., Holman, E., Joffe, A., \& Sibinga, E. (2017). There is no performance, there is just this moment: the role of mindfulness instruction in promoting health and well-being among students at a highly-ranked university in the united states. Journal of Evidence-Based Complementary \& Alternative Medicine, 22(4), 909-918. doi: 10.1177/2156587217719787

Kirby, J. N. (2016). Compassion interventions: the programmes, the evidence, and implications for research and practice. Psychology and Psychotherapy: Theory, Research and Practice, 90(3), 432-455. doi.org/10.1111/papt.12104.

Klingbeil, D. A., Renshaw, T. L., Willenbrink, J. B., Copek, R. A., Chan, K. T., Haddock, A., ... Clifton, J. (2017). Mindfulness-based interventions with youth: A comprehensive meta-analysis of group-design studies. Journal of School Psychology, 63(Supplement C), 77-103. doi: 10.1016/j.jsp.2017.03.006

Kounios, J., Frymiare, J. L., Bowden, E. M., Fleck, J. I., Subramaniam, K., Parrish, T. B., \& Jung-Beeman, M. (2006). The prepared mind: Neural activity prior to problem presentation predicts subsequent solution by sudden insight. Psychological Science, 17(10), 882-890. doi: 10.1111/j.1467-9280.2006.01798.x

Kounios, J., \& Beeman, M. (2014). The Cognitive Neuroscience of Insight. Annual Review of Psychology, 65(1), 71-93. doi: 10.1146/annurev-psych-010213-115154

Krathwohl, D. R. (2002). A revision of Bloom's taxonomy: An overview. Theory into practice, 41(4), 212-218. doi: 10.1207/s15430421tip4104_2

Lebuda, I., Zabelina, D. L., \& Karwowski, M. (2016). Mind full of ideas: A metaanalysis of the mindfulness-creativity link. Personality and Individual Differences, 93(Supplement C), 22-26. doi: 10.1016/j.paid.2015.09.040

Lòpez-Chávez, C., \& Shepherd, U. (2010). What is Expected of Twenty-FirstCentury Honors Students: An Analysis of an Integrative Learning Experience. Journal of the National Collegiate Honors Council 11. (2) Available at https://digitalcommons.unl.edu/nchcjournal/270/ [accessed 02/11/19] 
Lynch, S., Gander, M.-L., Kohls, N., Kudielka, B., \& Walach, H. (2011). Mindfulnessbased coping with university life: A non-randomized wait-list-controlled pilot evaluation. Stress and Health, 27(5), 365-375. doi: 10.1002/smi.1382

MacLean, K. A., Ferrer, E., Aichele, S. R., Bridwell, D. A., Zanesco, A. P., Jacobs, T. L., ... others. (2010). Intensive meditation training improves perceptual discrimination and sustained attention. Psychological Science, 21(6), 829-839. doi:

10.1177/0956797610371339

Malinowski, P. (2013). Neural mechanisms of attentional control in mindfulness meditation. Frontiers in neuroscience, 7, 8. doi: 10.3389/fnins.2013.00008

McKenzie, K., Murray, K. R., Murray, A. L., \& Richelieu, M. (2015). The effectiveness of university counselling for students with academic issues. Counselling and Psychotherapy Research, 15(4), 284-288. doi.org/10.1002/capr.1203Moran, T. P. (2016). Anxiety and working memory capacity: A meta-analysis and narrative review. Psychological Bulletin, 142(8), 831-864. doi: 10.1037/bul0000051

Mrazek, M. D., Franklin, M. S., Phillips, D. T., Baird, B., \& Schooler, J. W. (2013). Mindfulness Training Improves Working Memory Capacity and GRE Performance While Reducing Mind Wandering. Psychological Science, 24(5), 776-781. doi: 10.1177/0956797612459659

Mrazek, M. D., Smallwood, J., \& Schooler, J. W. (2013b). Mindfulness and mind-wandering: finding convergence through opposing constructs. Emotion, 12(3), 442. doi: 10.1037/a0026678Neff, K. D., \& Germer, C. K. (2013). A pilot study and randomized controlled trial of the mindful self-compassion program. Journal of clinical psychology, 69(1), 28-44. doi.org/10.1002/jclp.21923

Newby, P. (2010). Research methods for education. London: Pearson Education.

MFS (2018, July) Mindfulness for Students. Mindfulness courses at UK Universities. [accessed 27/08/2019]. Available from:

http://mindfulnessforstudents.co.uk/mindfulness-courses-at-uk-universities/

Ostafin, B. D., \& Kassman, K. T. (2012). Stepping out of history: Mindfulness improves insight problem solving. Consciousness and cognition, 21(2), 1031-1036. doi: 10.1016/j.concog.2012.02.014

Ostafin, B. D., Robinson, M. D., \& Meier, B. P. (Eds.). (2015). Handbook of Mindfulness and Self-regulation. New York: Springer.

Quaglia, J. T., Brown, K. W., Lindsay, E. K., Creswell, J. D., \& Goodman, R. J. (2015). From conceptualization to operationalization of mindfulness. Handbook of mindfulness: Theory, research, and practice, 151-170.

Raichle, M. E. (2015). The brain's default mode network. Annual review of neuroscience, 38, 433-447. doi: 10.1146/annurev-neuro-071013-014030 
Regehr, C., Glancy, D., \& Pitts, A. (2013). Interventions to reduce stress in university students: A review and meta-analysis. Journal of affective disorders, 148(1), 1-11. doi: 10.1016/j.jad.2012.11.026

Ren, J., Huang, Z., Luo, J., Wei, G., Ying, X., Ding, Z., Luo, F. (2011). Meditation promotes insightful problem-solving by keeping people in a mindful and alert conscious state. Science China Life Sciences, 54(10), 961-965. doi: 10.1007/s11427-011-4233-3

Richardson, M., Abraham, C., \& Bond, R. (2012). Psychological correlates of university students' academic performance: a systematic review and metaanalysis. Psychological bulletin, 138(2), 353. doi: 10.1037/a0026838

Sanger, K. L., \& Dorjee, D. (2016). Mindfulness training with adolescents enhances metacognition and the inhibition of irrelevant stimuli: Evidence from event-related brain potentials. Trends in Neuroscience and Education, 5(1), 1-11. doi: 10.1016/j.tine.2016.01.001

Segal, Z. V., Williams, J. M. G., \& Teasdale, J. D. (2018). Mindfulness-based cognitive therapy for depression. $2^{\text {nd }}$ Ed. New York: Guilford Publications.

Sevilla-Llewellyn-Jones, J., Santesteban-Echarri, O., Pryor, I., McGorry, P., \& Alvarez-Jimenez, M. (2018). Web-based mindfulness interventions for mental health treatment: systematic review and meta-analysis. JMIR mental health, 5(3), e10278. doi: $10.2196 / 10278$

Shapiro, S. L., Carlson, L. E., Astin, J. A., \& Freedman, B. (2006). Mechanisms of mindfulness. Journal of clinical psychology, 62(3), 373-386. doi: 10.1002/jclp.20237

Shaw, R. (2010). Embedding reflexivity within experiential qualitative psychology. Qualitative Research in Psychology, 7(3), 233-243. doi: 10.1080/14780880802699092

Sipe, W. E., \& Eisendrath, S. J. (2012). Mindfulness-based cognitive therapy: theory and practice. The Canadian Journal of Psychiatry, 57(2), 63-69. doi: 10.1177/070674371205700202

Tang, Y. Y., Hölzel, B. K., \& Posner, M. I. (2015). The neuroscience of mindfulness meditation. Nature Reviews Neuroscience, 16(4), 213. doi: 10.1038/nrn3916 Thorne, S. (2016). Interpretive description: Qualitative research for applied practice. Routledge.

Tomlinson, E. R., Yousaf, O., Vittersø, A. D., \& Jones, L. (2018). Dispositional mindfulness and psychological health: a systematic review. Mindfulness, 9(1), 23-43. doi:10.1007/s12671-017-0762-6Vickery, C. E., \& Dorjee, D. (2016). Mindfulness training in primary schools decreases negative affect and increases meta-cognition in children. Frontiers in Psychology, 6, 2025. doi: 10.3389/fpsyg.2015.02025

Weare, K., \& Huppert, F. (2019). Mindfulness and Education. Oxford Bilbiographies, Psychology. Feburary 2019. doi: 10.1093/obo/9780199828340-0236 
Weyandt, L., DuPaul, G. J., Verdi, G., Rossi, J. S., Swentosky, A. J., Vilardo, B. S., ... Carson, K. S. (2013). The Performance of College Students with and without ADHD: Neuropsychological, Academic, and Psychosocial Functioning. Journal of Psychopathology and Behavioral Assessment, 35(4), 421-435. doi: 10.1007/s10862013-9351-8

Williams, M., \& Kabat-Zinn, J. (Eds.). (2013). Mindfulness. London New York: Routledge.

Williams, M., Penman, D., \& Kabat-Zinn, J. (2011). Mindfulness: a practical guide to finding peace in a frantic world. London: Piatkus.

Wilson, A. C., Mackintosh, K., Power, K., \& Chan, S. W. (2019). Effectiveness of selfcompassion related therapies: A systematic review and meta-analysis. Mindfulness, 10(6), 979-995. doi.org/10.1007/s12671-018-1037-6

Winne, P. H. (2017). Cognition and metacognition within self-regulated learning. In Handbook of self-regulation of learning and performance (pp. 52-64). London: Routledge.

Zeidan, F., Johnson, S. K., Diamond, B. J., David, Z., \& Goolkasian, P. (2010). Mindfulness meditation improves cognition: Evidence of brief mental training. Consciousness and cognition, 19(2), 597-605.

doi.org/10.1016/j.concog.2010.03.014

\section{Table 1 The Distribution of Exam Grades in the Mindful Student Study Randomised Control Trial: Galante et al. (2018)}

\section{Distribution of Exam Grade in the Mindful Student Study (Galante et al., 2018)}

The Mindful Student Study to which this qualitative investigation is a follow-on study, used a randomised control trial to investigate the impact on university students $(n=616)$ of attending an eight-week mindfulness course. Students who attended the mindfulness course compared to the waitlist control group, were significantly, and with a moderate effect size less distressed during exam time $(\beta-0.44,95 \% \mathrm{Cl}-0.60$ to $-0.29 ; p<0.001)$. At exam time $57 \%$ of the control group had distress scores above the clinical threshold, whereas in the mindfulness group this reduced to $35 \%$ above the threshold. The Mindful 


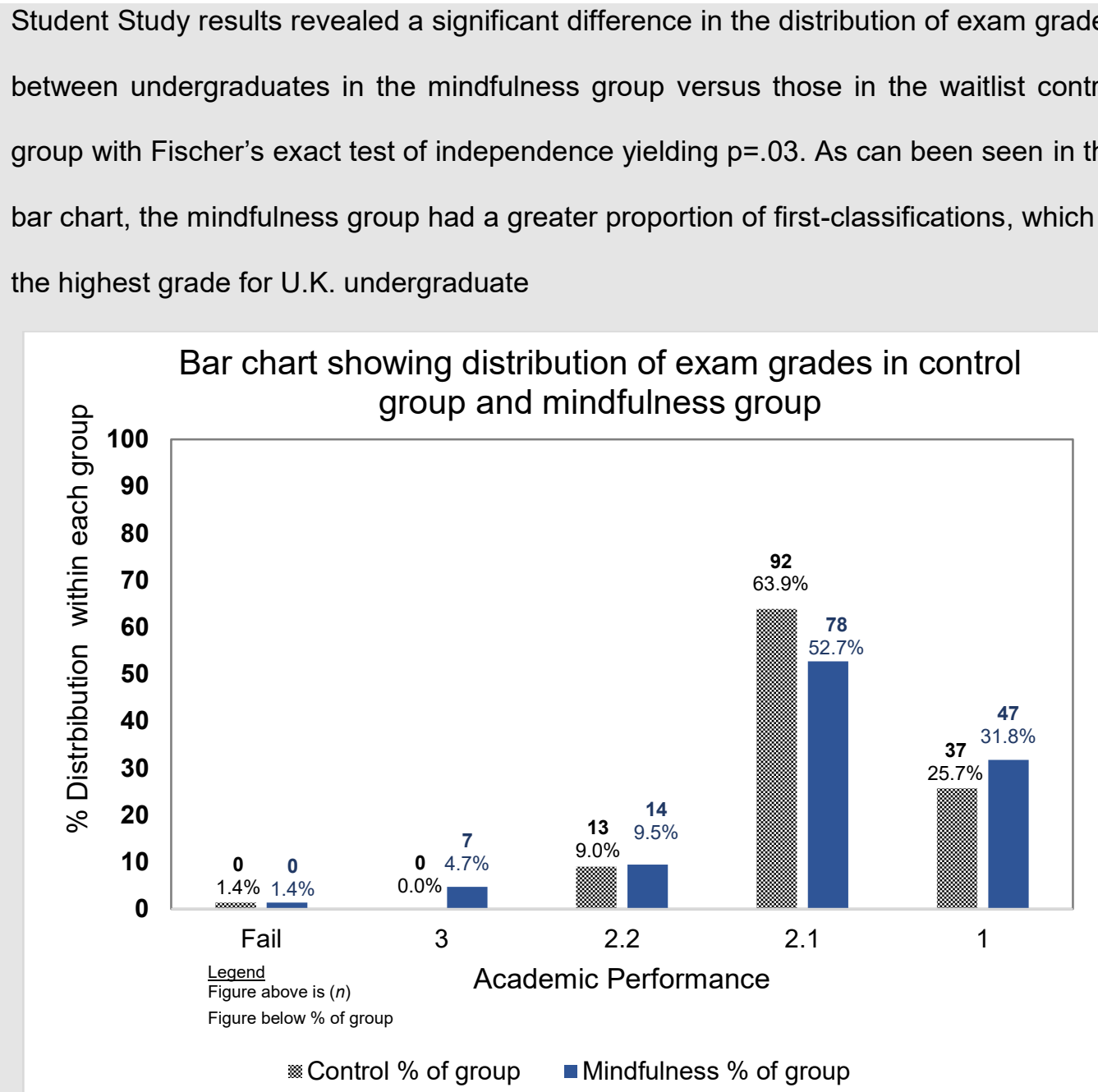

degree, but also a greater proportion of third-classifications, the lowest grade above a fail. Students in the mindfulness group who got lower grades were not more distressed than those who got higher grades, indicating that the intervention reduced their distress too in spite of their lower performance. Given that the statistical significance of this finding is borderline, and that many secondary outcomes were measured increasing the risk of multiple testing problems, this finding could be spurious. Furthermore, since a passive control group was used, non-specific effects, such as expectancy beliefs and group effects might account for the results. However, if the effect of mindfulness on academic performance is real, the implications for higher education institutions are important so the findings merit further research and provide the rationale for the current study. 
Table 2 Summary of Participant Characteristics 


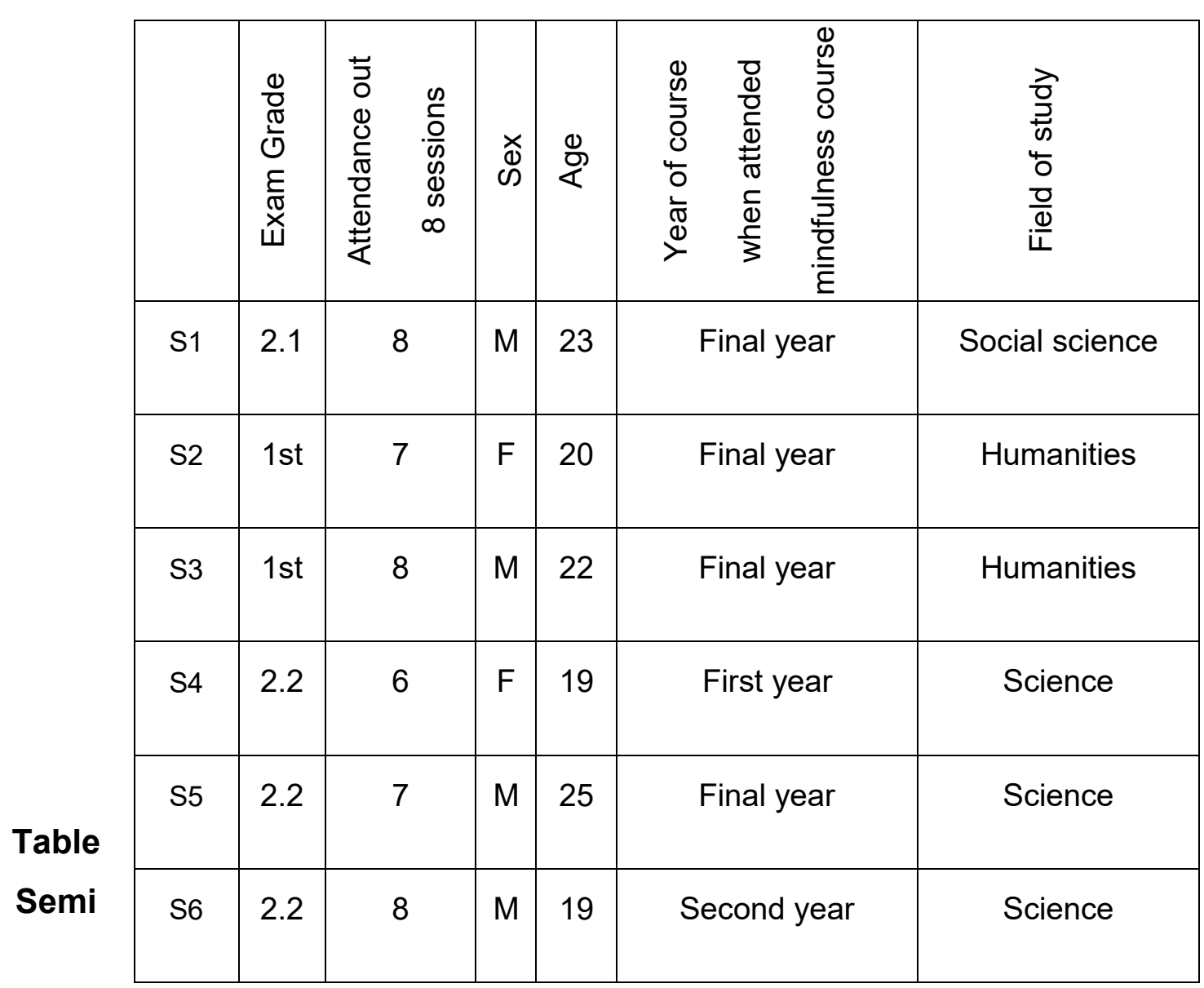

Structured Interview Schedule with explanations and justifications

\begin{tabular}{|c|c|c|}
\hline $\begin{array}{l}\text { Interview } \\
\text { part }\end{array}$ & $\begin{array}{c}\text { Question and comments made } \\
\text { by interviewer }\end{array}$ & $\begin{array}{l}\text { Explanation and } \\
\text { Justification }\end{array}$ \\
\hline \multirow[t]{2}{*}{$\begin{array}{l}\text { Main body } \\
60-90 \text { mins }\end{array}$} & $\begin{array}{l}\text { 1) Can we start with you just telling me a little about } \\
\text { your experience of attending the mindfulness } \\
\text { course? }\end{array}$ & $\begin{array}{l}\text { The first interview question inviting } \\
\text { students to describe their experience of } \\
\text { attending the mindfulness course is a very } \\
\text { broad and open-ended question. It was } \\
\text { designed to be an easy question for } \\
\text { students to respond to and to reveal } \\
\text { whatever they felt was most pertinent to } \\
\text { them about their experience of the having } \\
\text { attended the mindfulness course. The } \\
\text { question may also have helped to establish } \\
\text { rapport at the beginning of the interview. } \\
\text { Cohen et al., (2011, p275) states that open } \\
\text { ended questions "encourage co-operation } \\
\text { and help establish rapport; and they allow } \\
\text { the interviewer to make a truer assessment } \\
\text { of what the respondent really believes". }\end{array}$ \\
\hline & $\begin{array}{l}\text { 2) Do you feel that attending the mindfulness course } \\
\text { had an impact, if any, on your studying and revision } \\
\text { and academic performance. }\end{array}$ & $\begin{array}{l}\text { Another opened ended question. The } \\
\text { qualifier, if anything, was included in order } \\
\text { to avoid leading the student to assume that } \\
\text { I expected to hear "good" things about } \\
\text { attending the mindfulness course. Open } \\
\text { questions made it easier to follow up the } \\
\text { students' answers with a secondary } \\
\text { probing questions to seek elaboration. }\end{array}$ \\
\hline
\end{tabular}




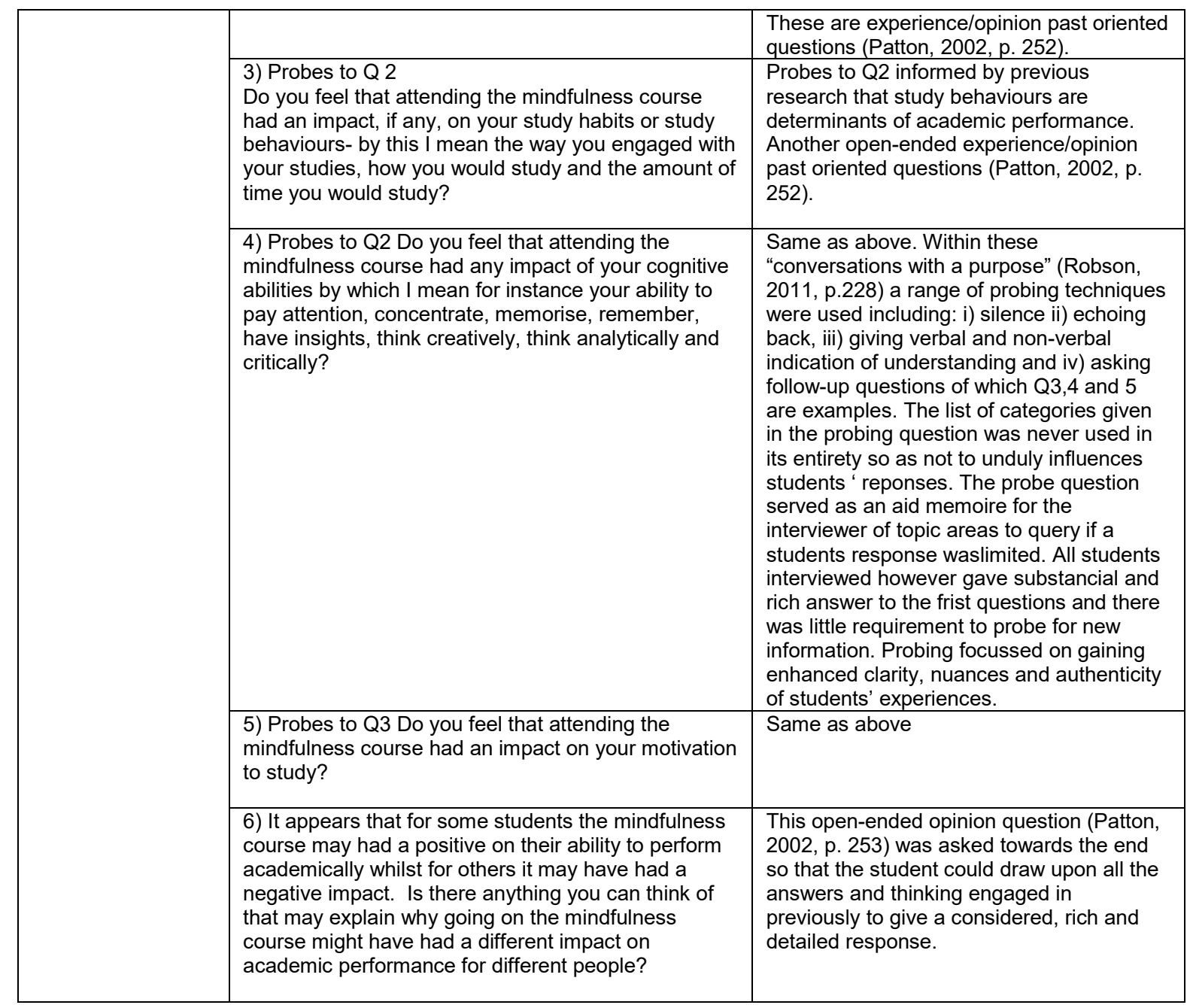


Table 4 Coding Table Showing Correspondence Between Global Theme Secondary Codes and Participants Statements

\begin{tabular}{|c|c|c|}
\hline $\begin{array}{l}\text { Global } \\
\text { themes }\end{array}$ & Secondary codes & Statements \\
\hline \multirow{7}{*}{$\begin{array}{l}\text { Positive influence of } \\
\text { mindfulness on } \\
\text { academic performance }\end{array}$} & Reduced academic distress & $\begin{array}{l}\text { "It helped me as a person cope with stress of deadlines... it made the whole term a lot less stressful } \\
\text { including revising" S3 "I would use the mindfulness in the exam, which I found really reduced my anxiety } \\
\text { level" S4 }\end{array}$ \\
\hline & Enhanced energy and stamina for studying & The more I practised the more energised and up to studying I felt if I had a difficult day" S4 \\
\hline & Greater enjoyment of studying & $\begin{array}{l}\text { "Mindfulness just made me relax a lot more and enjoy my subject a lot more... I like going to lectures } \\
\text { now and I like being there..." S6 }\end{array}$ \\
\hline & Reduced procrastination & $\begin{array}{l}\text { "I've always had a big problem with procrastinating which led to stress...I didn't have that so much } \\
\text { when I was doing the mindfulness" S3 }\end{array}$ \\
\hline & $\begin{array}{l}\text { Enhanced creativity, integrative thinking \& } \\
\text { insight }\end{array}$ & $\begin{array}{l}\text { "It helped with my creativity... sort of, link in different parts of the course to the essay... it helped me to } \\
\text { be able to do that... to think outside the box... I was able to come up with more original ideas" } 44\end{array}$ \\
\hline & Enhanced analytical thinking & "I was able to come up with more analytical points" S2 \\
\hline & Enhanced memory & "Mindfulness has helped me avoid doing things by rote... it helped with my memory in exams" S4 \\
\hline $\begin{array}{l}\text { Negative influence of } \\
\text { mindfulness on academic } \\
\text { performance }\end{array}$ & $\begin{array}{l}\text { Negative influence of mindfulness on } \\
\text { academic performance }\end{array}$ & $\begin{array}{l}\text { "It would have an impact on my grades cos like I didn't work so intensely. Cos, I would feel, I'm not } \\
\text { enjoying this, this is becoming a burden, I'm going to stop and do something else. Which... has been } \\
\text { really great for me but probably not great for my grades!" S6 }\end{array}$ \\
\hline \multirow{6}{*}{$\begin{array}{l}\text { Enhanced self-awareness } \\
\text { and self-regulation }\end{array}$} & Awareness of thinking & $\begin{array}{l}\text { "I'm able to recognise thoughts and perceive them much better than before. When I'm stressed about } \\
\text { something I realise that oh, I'm thinking this again" S1 }\end{array}$ \\
\hline & Regulation of thinking & $\begin{array}{l}\text { "In exams I struggled in the first year especially with anxiety, it made it really really hard for me to } \\
\text { retrieve things I knew I knew. After the mindfulness, I was sort of able to really sense myself and } \\
\text { retrieve the things that I knew were in there" S4 }\end{array}$ \\
\hline & Awareness of emotions & "Mindfulness makes you more sensitised to your emotional state" S2 \\
\hline & Regulation of emotions & $\begin{array}{l}\text { "I also found that if I was stressed before exams, it [mindfulness] was a really good way to calm myself } \\
\text { down" S4 }\end{array}$ \\
\hline & Awareness of behaviours & $\begin{array}{l}\text { "Mindfulness make me more aware... it definitely helped me to take study breaks... it helped me to treat } \\
\text { myself in a way that I would treat someone else. It helped me stop studying to the point of exhaustion } \\
\text { and with other things like remembering to feed myself and do exercise" S4 }\end{array}$ \\
\hline & Regulation of behaviours & $\begin{array}{l}\text { "After mindfulness, I started doing more physical exercise and recognised l'd been going out quite a lot } \\
\text { in the previous terms and drinking a lot of alcohol, so I completely cut back on my alcohol consumption" } \\
\text { S3 } \\
\text { "[mindfulness helps me] be organised and just focus on... my to-do list and really prioritise better and } \\
\text { allow myself some rest time as well" S1 }\end{array}$ \\
\hline
\end{tabular}


Table 5 Showing Perceived influences of Mindfulness on academic performance Among Six University Students who Attended an 8-week Mindfulness Course

\begin{tabular}{|c|c|c|}
\hline \multicolumn{2}{|c|}{ Perceived positive \& negative influences of mindfulness on academic performance } \\
\hline $\begin{array}{c}\text { Positive indirect impact } \\
\text { Six students }\end{array}$ & $\begin{array}{c}\text { Positive direct impact } \\
\text { Four students }\end{array}$ & One student \\
\hline Distress lessened & Supports creativity, & Time spent studying \\
& integrative thinking \& insight & reduced \\
\hline Supports energy \& stamina & Supports analytical thinking \\
for study & \\
\hline Supports enjoyment of & Supports memory \& & \\
studying & understanding & \\
& \\
\hline Procrastination lessened & \\
& \\
\end{tabular}


Fig 1. Thematic Network of Perceived Positive Influences of Mindfulness on Academic Performance
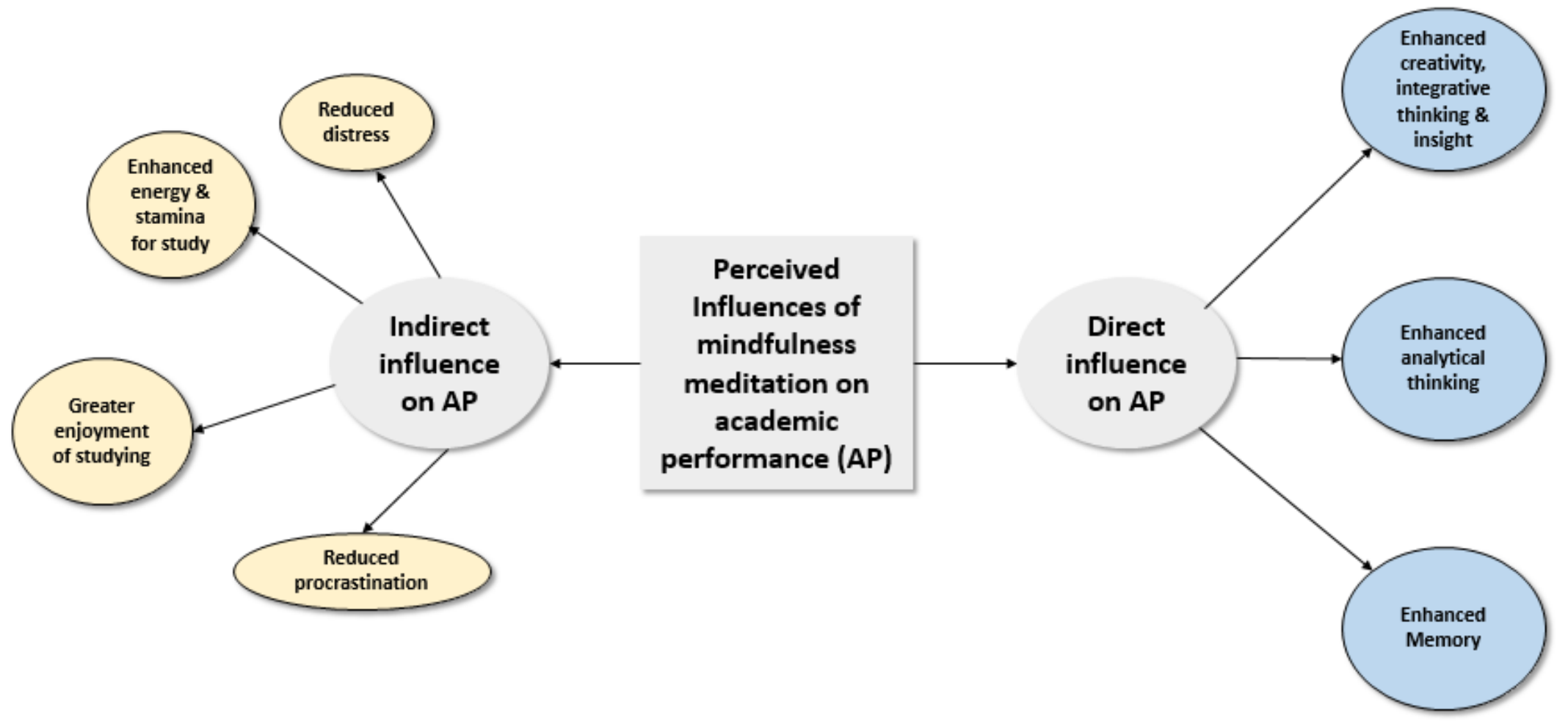


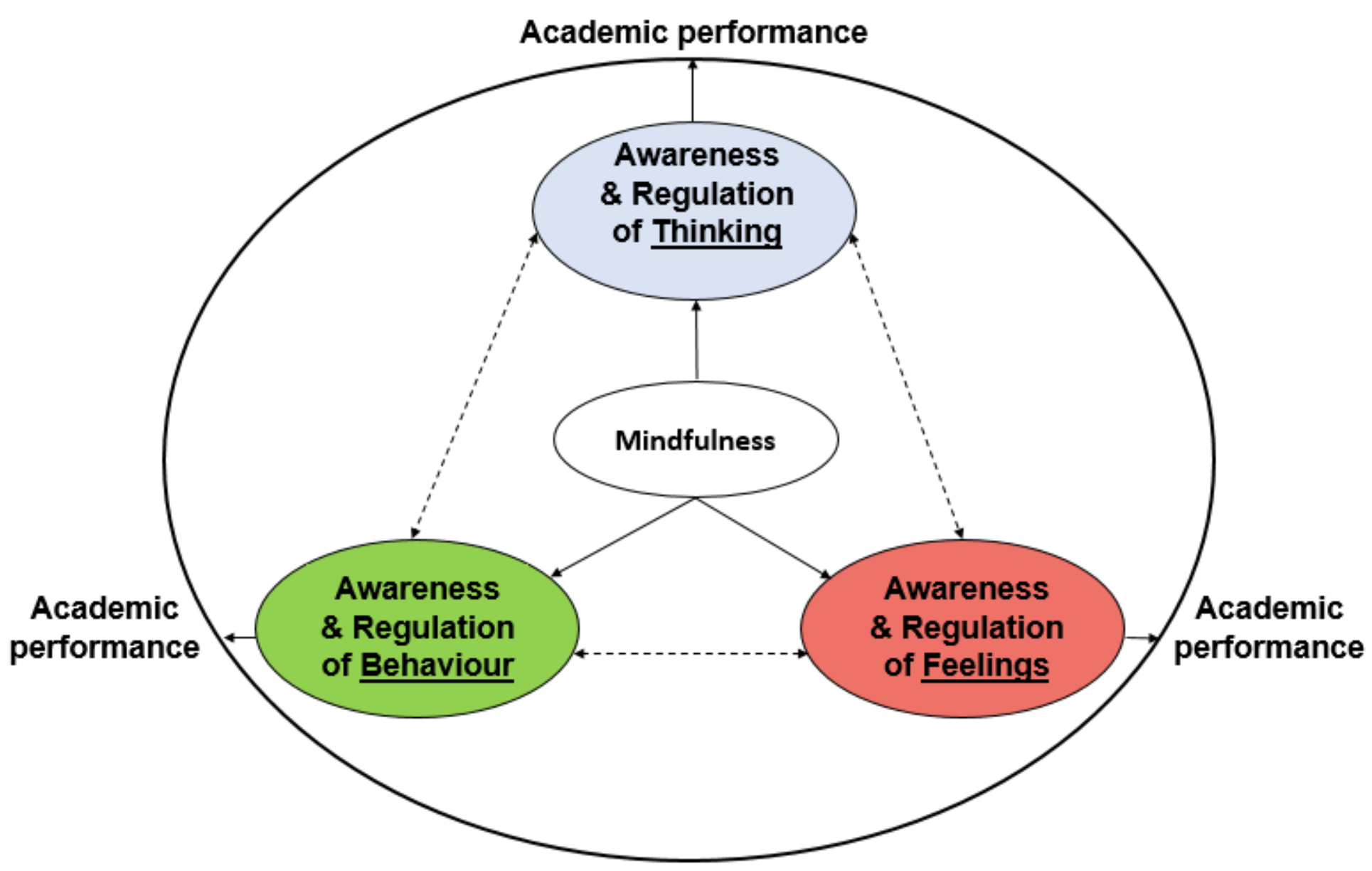

Fig 2. Thematic Network of Self-awareness and Self-regulation Theme 